\title{
Effect of Olibanum (Boswellia thurifera) as a feed additive on performance, some blood biochemical and intestinal morphology in broiler chicks
}

\author{
Sayeed Nouraldin Tabatabaei
}

Department of Animal Sciences, Khorasgan (Isfahan) Branch, Islamic Azad University, Isfahan, Iran

\begin{abstract}
Article history
Received: 7 Mar, 2016

Revised: 20 May, 2016

Accepted: 27 May, 2016

Abstract
To determine the effect of Olibanum on performance, some blood biochemical and
intestinal morphology of broiler chicks, a total 360 one day Ross 308 broiler chicks
were divided into 6 dietary treatments. The chicks were fed a basal diet as control;
basal diet with $0.01 \%$ (T1), $0.015 \%(\mathrm{~T} 2), 0.02 \%(\mathrm{~T} 3), 0.03 \%$ (T4) and $0.05 \%$ (T5) of
Olibanum. No significant difference was found in feed intake, weight gain and feed
conversion ratio between the control and treated groups. Serum triglyceride level
decreased significantly $(\mathrm{P}<0.05)$ in T1, T2 and T3 compared to the control. Villus
length of ilium increased significantly ( $\mathrm{P}<0.05)$ in T2. In conclusion, it seems that
inclusion of Olibanum as feed additive may have significantly enhanced effects on
performance and some blood biochemical in broiler chicks.
Keywords: Performance; broilers; blood parameters; Olibanum; intestinal morphology
\end{abstract}

To cite this article: Tabatabaie SN, 2016. Effect of Olibanum (Boswellia thurifera) as a feed additive on performance, some blood biochemical and intestinal morphology in broiler chicks. Res. Opin. Anim. Vet. Sci., 6(4): 130-134.

\section{Introduction}

Herbal, spices, as feed additives are possible natural alternatives to the use of antibiotics and probiotics as growth promoters in broiler diets. The effect of a phytogenic feed additive on nutrient digestibility has been well illustrated in many studies (Demir et al., 2003; Ghaedi et al., 2014). Herbal feed additives are plant derived products used in poultry feeding to improve the consumption and conversion of food, and the digestibility and weight gain of broiler chickens (Moorthy et al., 2009). Boswellia is a genus of trees in the order Sapindales, known for their fragrant resin which has many pharmacological uses, particularly as anti inflammatory (Etuk et al., 2006). Also, the aqueous stem bark extract of Boswellia was reported to show anti ulcer activity and reduced gastrointestinal motility (Nwinyi et al., 2004) and to possess anti diarrheal effect, which may be related to anti cholinergic mechanisms (Etuk et al., 2006). Crude extracts of the stem bark of Boswellia have been found to antibacterial activity against both Gram-positive and Gram-negative bacteria (Olukemi et al., 2005). Boswellia serrata resin is included in the group of feed additives approved for use in poultry production according to the European Union register of feed additives pursuant to regulation (EC) No 1831.2003. The resin of Boswellia species originates from India, Pakistan, Africa, and the Arabian Peninsula, where it is obtained from trees of the Burseraceae family. It is also known as "frankincense", "olibanum", "salai guggal", "loban" or "kundur" (Afsharypuor and Rahmany, 2005) and is famous as a traditional medicine of the East. It contains mono (13\%) and diterpenes $(40 \%)$ as well as ethyl acetate $(21.4 \%)$, octyl acetate (13.4\%), and methylanisole $(7.6 \%)$. The main biological activity

\footnotetext{
*Corresponding author: Sayeed Nouroldin Tabatabaie, Department of Animal Science, Islamic Azad University, Isfahan (Khorasgan) branch, Isfahan, Iran
} 
among terpenes is attributed to 11-keto- $\beta$-acetyl-betaboswellic acid, acetyl-11-keto-ß-boswellic acid and acetyl- $\alpha$-boswellic acid (Camarda et al., 2007). Singh et al. (2007) found that a dose of the pure Boswellia serrata at the level of $500 \mathrm{mg} / \mathrm{kg}$ of body weight was sufficient to inhibit their growth. In another study, a positive correlation was found between the antioxidant activity and sustenance of the integrity and activity of intestinal epithelium (Catanzaro et al., 2015). Herbs have been used as a feed additive in poultry diet for a long time to improve the growth and performance (Great head, 2003; Gill, 2009). The objective of this study was to explore the potential uses of different levels of Olibanum on performance, some blood biochemical and intestinal morphology in broiler chicks.

\section{Materials and Methods}

\section{Birds and management}

This experiment was carried out at the aviculture farm belong to the Islamic Azad University, Isfahan (Khorasgan) branch, Isfahan, Iran. All the experimental procedures were in accordance with established standards for the care and use of animal's rights for research purposes. For evaluating the effect of Olibanum powder on performance of broiler chicks, a total 360 one day broilers chicks (Ross 308) was divided into 6 groups of 10 birds each and assigned to 4 treatment diets. The experiment was carried out in 6 weeks. Feed and fresh water were provided ad libitum during this experiment. A lighting programmed of $23 \mathrm{~L}$ : 1D was used for the trial period. The chicks were fed a basal diet as control; basal diet with $0.01 \%$ (T1), 0.015 $\%$ (T2), $0.02 \%$ (T3), $0.03 \%$ (T4) and $0.05 \%$ (T5) of Olibanum. Their diets were balanced according to the NRC (1994) as shown in Table 1. The body weight gain; feed consumption and feed conversion efficiency were measured weekly.

\section{Blood biochemical evaluation}

At the end of the trial, 2 male chicks from each treatment were slaughtered. Blood samples from each bird were collected and stored in refrigerator at $4^{\circ} \mathrm{C}$ for $24 \mathrm{~h}$ and then they were subjected to biochemical determination (Pars Azmoon commercial kits).

\section{Histomorphometric examination of small intestine}

Samples of the intestines after the separation were fixed in Bouin's solution (Gabe, 1976), dehydrated, and paraffin-embedded. Longitudinal, 6-7 $\mu \mathrm{m}$ thick, consecutive paraffin sections were prepared and stained with hematoxylin eosin (HE) (Zawistowski, 1986). Morphometric analyses were performed on the duodenum and jejunum of 2 broilers per each treatment. The preparations were analyzed under a light microscope Axio Imager (Carl Zeiss MicroImaging $\mathrm{GmbH}$, Göttingen, Germany). Patches with a correct structure were scanned with a Mirax Desk scanner (Carl Zeiss Microscopy GmbH, Jena, Germany). The measurements of the intestinal structures were performed using the Zeiss Axiovision LE image analysis program, ver. 4.1. (Zeiss MicroImaging GmBH, Jena, Germany).

\section{Data analysis}

Data were collected and analyzed using the General linear model procedure of SAS (2001). Differences between means were analyzed by Duncan's multiple range test (1995) and $P$ value less than 0.05 was considered as significant. The data were analyzed according to the following model:

$Y i j=\mu+T i+e i j$.

Whereas: $\mathrm{Y}$ ij $=$ Average effect observed, $\mu=$ Total average, $\mathrm{T} i \mathrm{i}=$ Effect of treatments, $\mathrm{e} i \mathrm{j}=$ Effect of errors.

\section{Results and Discussion}

Data in Table 2 showed a non-significant difference in FI in trial groups. The lowest feed intake was found in the treated groups compared to the control. Also the highest BW belonged to the control group, but the enhanced FCR was recorded in T2 and T3.

Table 1: Composition of the experimental diets for experimental chicks

\begin{tabular}{lccc}
\hline Ingredients \% & $\begin{array}{c}0-14 \\
\text { (days) }\end{array}$ & $\begin{array}{c}14-21 \\
\text { (days) }\end{array}$ & $\begin{array}{c}21-42 \\
\text { (days) }\end{array}$ \\
\hline Corn grain & 54 & 54.7 & 60.1 \\
Soybean meal & 40 & 38.7 & 33.15 \\
Vegetable oil & 1.5 & 3 & 3 \\
Dicalcium phosphate & 2 & 1.7 & 1.6 \\
Oyster shells & 1.0 & 0.9 & 1.2 \\
Methionine DL & 0.3 & 0.2 & 0.1 \\
Lysine L & 0.17 & 0 & 0.10 \\
NaCl & 0.25 & 0.30 & 0.25 \\
Vitamin Premix* & 0.25 & 0.25 & 0.25 \\
Mineral Premix & 0.25 & 0.25 & 0.25 \\
\hline Calculated nutrient content & & & \\
\hline ME(kcal.kg) & 2810 & 2980 & 3050 \\
CP (\%) & 21.5 & 21 & 20 \\
Ca (\%) & 0.97 & 0.86 & 0.81 \\
Available Phosphorus (\%) & 0.46 & 0.43 & 0.40 \\
Lysine (\%) & 1.32 & 1.19 & 1.17 \\
Methionine + Cystine (\%) & 1.00 & 0.90 & 0.82 \\
\hline Suppliod per kilogram & &
\end{tabular}

Supplied per kilogram of feed: 7.500 IU of vitamin A, 2000 IU vitamin D3, $30 \mathrm{Mg}$ vitamin $\mathrm{E}, 1.5 \mu \mathrm{g}$ vitamin $\mathrm{B} 12,2 \mathrm{mg}$ B6, 5 mg vitamin $\mathrm{K}, 5 \mathrm{mg}$ vitamin B2, $1 \mathrm{mg}$ vitamin B1, 40 $\mathrm{mg}$ nicotinic acide, $160 \mu \mathrm{g}$ vitamin Biothine, $12 \mathrm{mg}$ calcium pantothenate, $1 \mathrm{mg}$ folic acid, $20 \mathrm{mg} \mathrm{Fe}, 71 \mathrm{mg} \mathrm{Mn}, 100 \mu \mathrm{g}$ Se, $37 \mathrm{mg} \mathrm{Zn,} 6 \mathrm{mg} \mathrm{Cu}, 1.14 \mathrm{mg} \mathrm{I}, 400 \mu \mathrm{g} \mathrm{Cu}$ 
Table 2: The effect of added experimental diets on broilers performance (0-42 days)

\begin{tabular}{cccc}
\hline Treatments & FI $(\mathrm{g} /$ day $)$ & BW $(\mathrm{g} /$ day $)$ & FCR \\
\hline Control & 89.07 & 45.70 & 1.95 \\
$\mathrm{~T}_{1}$ & 87.76 & 45.21 & 1.94 \\
$\mathrm{~T}_{2}$ & 86.43 & 44.74 & 1.93 \\
$\mathrm{~T}_{3}$ & 86.20 & 42.57 & 2.02 \\
$\mathrm{~T}_{4}$ & 85.54 & 42.69 & 2.01 \\
$\mathrm{~T}_{5}$ & 85.64 & 43.30 & 1.99 \\
$\mathrm{SEM}$ & 2.90 & 1.43 & 0.11 \\
\hline
\end{tabular}

The improved feed efficiency in treated groups may be due to the digestive characteristics of Oilbanum included in the broiler diet in spite of the low consumption compared with other may be due to the fact that it contains some compounds that enhance digestion and absorption of some nutrients in the diet. Gupta et al. (2001) confirmed that the dietary supplementation with the Boswellia serrata resin increases the absorption of iron, calcium, and phosphorus, which can also contribute to improved digestibility of dry matter and organic matter in the feed. Krieglstein et al. (2002) further confirmed that Boswellia resins appear to stimulate digestive functions, reduce gases, and enhance the flow of digestive juices. Other researchers proved that there is an increase in BW, FCR with decreasing haematological values of some important blood parameters using herbs in broiler diet (Ghaedi et al., 2014; Kheiri et al., 2014: Rafiee et al., 2014). The results of the present study are in agreement with the above findings.

Data from this study showed that the serum cholesterol, high density lipoprotein (HDL), low density lipoprotein (LDL) did not change significantly by the experimental diets (Table 3 ). Triglyceride level was at the lowest when chicks were fed $T_{2}$ where Olibanum caused a significant decrease in blood triglyceride. As results revealed from this study, although alanine transaminase (ALT), aspartate transaminase (AST) and alkaline phosphatase (ALK) enzymes tended to decrease by using Olibanum, but there were no significant differences between treatments and compared to the control. Qurishi et al. (2010) observed that boswellic acid stimulates secretion of pancreatic enzymes leading to an improvement of protein and energy digestibility, a reduction of endogenous losses of nitrogen and ammonia, and production of other microbial metabolites. Result of Roseline et al. (2007) reported that the Boswellia dalzielii bark extract did not have any significant $(\mathrm{P}>0.05)$ effect on alkaline phosphatase (ALP) activity in general. However, at 150 $\mathrm{mg} / \mathrm{kg}$, ALP activity showed a decrease, which still was not statistically significant. They also demonstrated that there was a significant dose dependent decrease in the activities of AST and ALT in the treated groups as compared to the control. In fact, natural flavonoids and polyphenolic compounds in Boswellia have been reported to exhibit protective and strengthening activities on liver cells (Akamatsu et al., 2004). The positive effect of supplements such as herbs, spices, plant extracts, or essential oils on the gastrointestinal tract and the production performance of animals is widely described in the literature (Jamroz et al., 2006; Abdel-Rahman et al., 2014).

The effect of Olibanum supplementation on intestinal morphology is given in Table 4. Data showed that in duodenum and jejunum villus length and crypt depth increased none significantly. There was a significant increase in villus length only in the ileum. It can be hypothesized that, in the current experiment, increased integrity of the intestinal tract associated with a greater villus length, height and surface area after Olibanum supplementation resulted in improved performance and other blood biochemical in broiler chickens. An increase in the height of the intestinal villi and the villus crypt ratio is directly correlated with an increase in the cellular turnover in the epithelium. A reduction of intestinal crypts indicates a decrease in the exchange of enterocytes and a lower requirement of tissue development (Pluske et al., 1996; Samanya and Yamauchi, 2002). Hartmann et al. (2014) observed a reduction of the inflammatory condition and swelling in the intestinal submucosa of rats and reduced damage of the epithelium lining the crypts after the use of Boswellia serrata.

Table 3: The effect of added experimental diets on some blood biochemical

\begin{tabular}{lccccccc}
\hline Treatments & $\begin{array}{c}\text { Cholesterol } \\
(\mathrm{mg} / \mathrm{dl})\end{array}$ & $\begin{array}{c}\text { Triglyceride } \\
(\mathrm{mg} / \mathrm{dl})\end{array}$ & $\begin{array}{c}\text { LDL } \\
(\mathrm{mg} / \mathrm{dl})\end{array}$ & $\begin{array}{c}\text { HDL } \\
(\mathrm{mg} / \mathrm{dl})\end{array}$ & ALT $(\mathrm{u} / \mathrm{l})$ & $\begin{array}{c}\text { AST } \\
(\mathrm{u} / \mathrm{l})\end{array}$ & $\begin{array}{c}\text { ALK } \\
(\mathrm{u} / \mathrm{l})\end{array}$ \\
\hline Control & 143 & $128^{\mathrm{a}}$ & 58 & 59 & 5.4 & 291 & 12.8 \\
$\mathrm{~T}_{1}$ & 133 & $95^{\mathrm{b}}$ & 48 & 67 & 3.2 & 256 & 9.6 \\
$\mathrm{~T}_{2}$ & 135 & $81^{\mathrm{b}}$ & 55 & 63 & 2.9 & 242 & 5.6 \\
$\mathrm{~T}_{3}$ & 131 & $94^{\mathrm{b}}$ & 49 & 63 & 3.3 & 220 & 6.8 \\
$\mathrm{~T}_{4}$ & 139 & $112^{\mathrm{ab}}$ & 55 & 61 & 2.6 & 249 & 7.1 \\
$\mathrm{~T}_{5}$ & 122 & $101^{\mathrm{ab}}$ & 43 & 59 & 5.1 & 250 & 12.2 \\
$\mathrm{SEM}$ & 10.23 & 8.34 & 2.11 & 4.65 & 0.23 & 23.61 & 0.43 \\
\hline
\end{tabular}

Means within column with no common on letter are significantly different $(\mathrm{P}<0.05)$; LDL: low density lipoprotein; HDL: high density lipoprotein; ALT: alanine transaminase; AST: aspartate transaminase; ALK: alkaline phosphatase 
Table 4: The effect of added experimental diets on broilers intestinal morphology

\begin{tabular}{lcccccc}
\hline Treatments & \multicolumn{2}{c}{ Duodenum $(\mu \mathrm{m})$} & \multicolumn{2}{c}{ Jejunum $(\mu \mathrm{m})$} & \multicolumn{2}{c}{ Ileum $(\mu \mathrm{m})$} \\
\hline Control & Villus Length & Crypt depth & Villus Length & Crypt depth & Villus Length & Crypt depth \\
$\mathrm{T}_{1}$ & 1421 & 163 & 870 & 129 & $578^{\mathrm{b}}$ & 102 \\
$\mathrm{~T}_{2}$ & 1669 & 195 & 1006 & 155 & $646^{\mathrm{ab}}$ & 133 \\
$\mathrm{~T}_{3}$ & 1595 & 171 & 1064 & 166 & $792^{\mathrm{a}}$ & 134 \\
$\mathrm{~T}_{4}$ & 1503 & 185 & 944 & 156 & $650^{\mathrm{ab}}$ & 109 \\
$\mathrm{~T}_{5}$ & 1602 & 177 & 1104 & 146 & $692^{\mathrm{ab}}$ & 101 \\
$\mathrm{SEM}$ & 1564 & 180 & 1001 & 154 & $723^{\mathrm{ab}}$ & 113 \\
\hline
\end{tabular}

Means within a column with no common on letter are significantly different $(\mathrm{P}<0.05)$.

\section{Conclusion}

We reported some beneficial effects of Olibanum on growth and some blood biochemical in broiler chicks. This improvement may be due to the biological functions to improve growth, digestibility and other activities.

\section{References}

Afsharypuor S, Rahmany M (2005) Essential oil Cconstituents of two African Olibanums available in Isfahan commercial market. Iran J Pharmac Sci 1: 167-170.

Akamatsu S, Watanabe A, Tamesada M, Nakamura R, Hayashi S, et al (2004) Hepatoprotective effect of extracts from Lentinus edodes mycelia on dimethylnitrosamine-induced liver injury. Biol Pharm Bull 27: 1957-1960.

Abdel-Rahman HA, Helal MA, Nafeaa AA, Zahran IS (2014) Effect of Turmeric (Curcuma Longa), Fenugreek (Trigonella foenum-graecum L) And/or Bioflavonoid supplementation to the broiler chicks diet and drinking water on the growth performance and intestinal. Global Vet 12: 627-635.

Catanzaro D, Rancan S, Orso G, Dall'Acqua S, Brun P, Giron MC,Carrara M, Castagliuolo I, Ragazzi E, Caparrotta L, Montopoli M (2015) Boswellia serrata Preserves Intestinal Epithelial Barrier from Oxidative andInflammatory Damage. PLoS ONE 10: e0125375.

Demir E, Sarica S, Ozcan MA, Suicmez M (2003) The use of natural feed additives as alternative for an antibiotic growth promoter in broiler diets. Br Poult Sci 44: 44-45

Etuk EU, Agaie BM, Onyeyili PA, Ottah CU (2006) Toxicological studies of aqueous stem bark extract of Boswellia dalzielii in albino rats. Indian J Pharmacol 38: 359-360.

Gabe M (1976) Histological Technigues. SpringerVerlag, Masson-Paris.

Ghaedi H, Nasr J, Kheiri, F, Rahimian Y, Miri Y (2014) The effect of virginiamycin andblack pepper (Piper nigrum L.) extract on performance of broiler chicks. Res Opin Anim Vet Sci 4: 91-95.

Gill C (2009) Herbs and plant extracts as growth enhancers. Feed Inter 4: 20-23.
Great head H (2003) Plants and plant extracts for improving animal productivity. Proc Nutr Soc 62: 279-290.

Gupta I, Parihar A, Malhotra P, Singh G, Ludtke R, Safayhi H, Ammon H (2001) Effects of gum resin of Boswellia serrata in patients with chronic colitis. Planta Med 67: 391-395.

Hartmann RM, Fillmann HS, Martins MI, Meurer L, Marroni NP (2014) Boswellia serrata has beneficial anti-inflammatory and antioxidant properties in a model of experimental colitis. Phytother Res 28: 1392-1398.

Jamroz D, Wertelecki T, Houszka M, Kamel C (2006) Influence of diet type on the inclusion of plant origin active substances on morphological and histochemical Unauthenticated characteristics of the stomach and jejunum walls in chicken. J Anim Physiol Anim Nutr 90: 255-268.

Kheiri F, Rahimian Y, Rafiee A (2014) Effect of Heracleum persicum extract on performance and some haematological parameters in broiler chicks. Res Opin Anim Vet Sci 4: 522-525.

Krieglstein CF, Anthoni C, Rijcken EJ, Laukötter M, Spiegel HU, BodenSE, Schweizer S, Safayhi H, Senninger N, Schürmann G (2001) Acetyl-11-keto- $\beta$ boswellic acid, a constituent of a herbal medicine from Boswelliaserrata resin, attenuates experimental ileitis. Int J Colorectal Dis 16: 88-95.

Camarda L, Dayton T, Di Stefano V, Pitonzo R, D (2007) Schillaci, Chemical composition and antimicrobial activity of some oleogum resin essential oils from Boswellia spp. (Burseraceae), Annali di Chimica, 97: 837-844.

Moorthy M, Ravikumar S, Viswanathan K, Edwin SC (2009) Ginger, pepper and curry leaf powder as feed additives in broiler diet. Inter J Poult Sci 8: 779-782.

National Research Council, NRC (1994) Nutrient Requirements of Poultry $9^{\text {th }}$ Ed. National Academy Press. Washington, DC. Of Alletchs $10^{\text {th }}$ annual symposium Nottingham University Press. Nottingham, UK.

Nwinyi, FC, Binda L, Ajoku GA, Aniagu SO, Gamaniel KS et al (2004) Evaluation of the aqueous extract of Boswellia dalzielii stems bark for antimicrobial 
activities and gastrointestinal effects. Afr J Biotechnol 3: 284-288.

Olukemi, MA, Kandakai-Olukemi YT, Mawak JD (2005) Antibacterial activity of the stem bark of Boswellia dalzielii. J Pharmacy Bioresour 2: 131-136.

Pluske JR, Thompson MJ, Atwood CS, Bird PH, Williams LH, Hartmenn PE (1996) Maintenance of villus height and crypt depth, and enhancement of disaccharide digestion and monosaccharide absorption, in piglets fed on cows' whole milk after weaning. Br J Nutr 76: 409-422.

Qurishi Y, Hamid A, Zargar MA, Singh SK, Saxena AK (2010) Potential role of natural molecules in health and disease: Importance of boswellic acid. J Med Plants Res 4: 2778-2785.

Rafiee A, F Kheiri, Y Rahimian, M Faghani, MR Valiollahi and Y Miri (2014) The effect ofginger root (Zingiber officinale) and cumin (Cuminum cyminum) powder on performance, some haematological traits and intestinal morphology of broiler chicks. Res Opin Anim Vet Sci 4: 96-100.

Roseline Aliyu, Donatien Gatsing and Kiri H Jaryum (2007) The Effects of Boswellia dalzielii (Burseraceae) Aqueous Bark Extract on Rat Liver Function. Asian J Biochem 2: 359-363.

Samanya M, Yamauchi K (2002) Histological alterations of intestinal villi in chickens fed dried Bacillus subtilis var. natto Comp Biochem Physiol 133: 95-104.

SAS Institute (2001) SAS/STAT User's Guide for Personal Computer. Relesse 6.12 SAS Institute, Inc, Cary NC, USA.

Singh B, R Kumar, S Bhandari, S Pathania and B Lai (2007) Volatile constituents of natural Boswellia serrata oleo-gum-resin and commercial samples, Flavour and Fragrance J, 22: 145-147.

Zawistowski S (1986) Histological Technique, Histology and Histopathology Basis (inPolish), 5th ed. PCWL, Warsaw (Poland). 